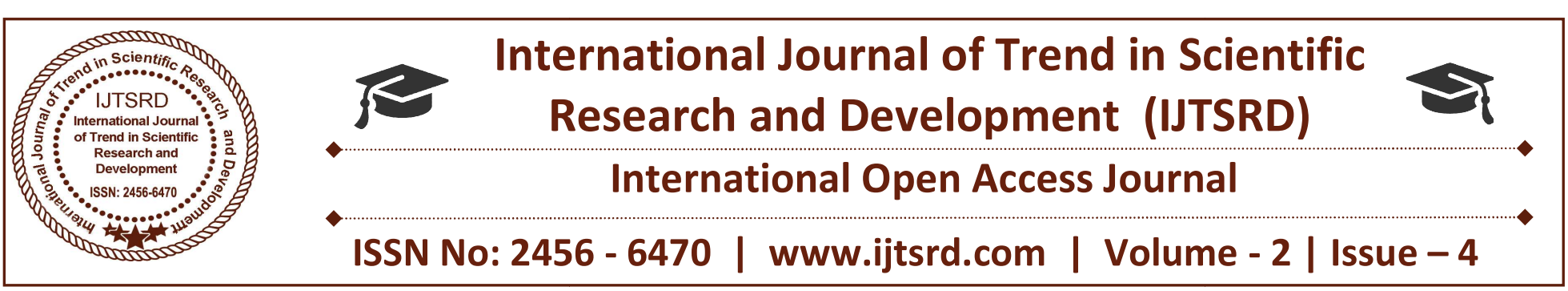

\title{
IoT based Water Saving Technique for Green Farming
}

\author{
Nurjaha Bagwan, Pradnya Kushire, Manasi Deshpande, Priyanka Singh, Prof. Shyam Gupta
}

Department of Computer Engineering, Savitribai Phule

Pune University, Pune, Maharashtra, India

\begin{abstract}
A decision Support System based on the combination of micro controllers and ADC and ANN Algorithm is proposed to support the irrigation management in agriculture. The farmers experience and the irrigation best practices are modelled through Artificial Intelligence and Neural Network Algorithm and the outputs of numerical soil and crop models are used to provide a context-aware and optimized irrigation schedule. The suggested actions are devoted to reduce the waste of water and to maximize the crop yield according to the weather conditions and the real water needs. The proposed methodology is embedded in the network gateway making the system a truly smart and autonomous wireless decision support system.
\end{abstract}

Keywords: Wireless Sensor Network, Smart Actuation, ANN algorithm, Decision Support System

\section{INTRODUCTION}

In the last years, the adoption of sensors for water management in agriculture has received an increasing attention with reference to the irrigation optimization and control. The most common sensors provide information about the soil status, such as the soil matrix potential, or the volumetric soil water content. Other sensors are devoted to measure the water quality and properties like the salinity. These sensors have been widely used in conjunction with wired instrumentation systems locally controlled by experts. More recently, with the development of the wireless sensor network (WSN) and of the wireless sensor and actuation network (WSAN) technologies the diffusion of embedded, low-cost, and autonomous sensing and actuation devices has considerably increased.
Different applications exploiting the distributed sensing features of WSNs arised, including environmental monitoring, emergency management, and more in general the smart cities and communities framework.

Thanks to the application oriented properties of the WSN/WSAN, such technologies are suitable platforms in to implement wireless systems for agricultural needs. The so-called precision agriculture has benefited from WSN/WSAN for the development of decision support systems (DSS) dedicated to improve the crop yield while preserving the environmental resources. The role of the farmers is becoming more and more complex due to the stringent requirements and regulations, and DSS tools are becoming attractive to support the daily management of the agricultural processes.

The goal of this work is to develop a simple and lowcost WSAN-based DSS to support the farmers in the management of the irrigation, preliminary presented by the same authors in. In particular, the DSS aims at (i) reducing the waste of irrigated water and (ii) improving the exploitation of the water resource by the cultivated crops.

\section{LITERATURE SURVEY}

Author: (1) Kalyan et al (2011):

The need for systems that make agriculture easier and more sustainable has increased within the past few years. The ability to con-serve two of the most important resources of a farmer, water and time, has been the latest challenge. A system that provides this 
ability - through the use of efficient and reliable methods such as wireless sensor networking, sprinkler irrigation, GSM, SMS technologies and readily available mobile phone devices ? is certain to help the farmers get a better yield and on a larger scale, help the agricultural and economic growth of the country.

Author: (2) Prisilla et al (2012)

Water is one of nature's most important gifts

to mankind, because of the increase in population food requirement for human being is also increasing. Over the past few decade usage of water for irrigation has increased hysterically. Water is polluted due to wastage and contaminants in the industries. Saving water is more important. This ultimate aim can be achieved by using the exiting ANN control system. It will provide a way to save flood water in the fields for future irrigation purpose

Author: (3) Shaik et al (2014) :

The water level monitoring in agricultural field and motor controlling system based on GSM technology using PIC16F877A micro-controller. An advantage of this system is very simple, more competent and low cost. Future work can be done by designing a sys-tem based on $3 \mathrm{G}$ camera for visual identification of water level from remote level.
Author: (4) Manish et al (2013):

The Automated Intelligent Wireless Drip Irrigation System Using Linear Programming provides to be a real time feedback control system which monitors and controls all the activities of drip irrigation system efficiently as well as it helps us for to do the efficient water management in order to get more profit with less cost. Using this system, one can save manpower, as well as water to improve productivity and ultimately the profit. In future if we modify it properly then this system can also supply agricultural chemicals like calcium, sodium, ammonium, zinc to the field along with Fertilizers with adding new sensors and valves.

Author: (5) Suraj et al (2015):

it provide irrigation as per the requirement of the crop. 2. This system is automated irrigation system so it reduces the human resources. 3 . This irrigation system was found to be feasible and cost effective for optimizing water resources for agricultural production. 4. The irrigation system can be adjusted to a variety of specific crop needs and requires minimum maintenance. Using this system we can monitor the status of all the sensors (Soil , moisture, Temperature, Water level) and also the ON/OFF status of the motor and Fan.

\section{PROPOSED ARCHITECTURE}
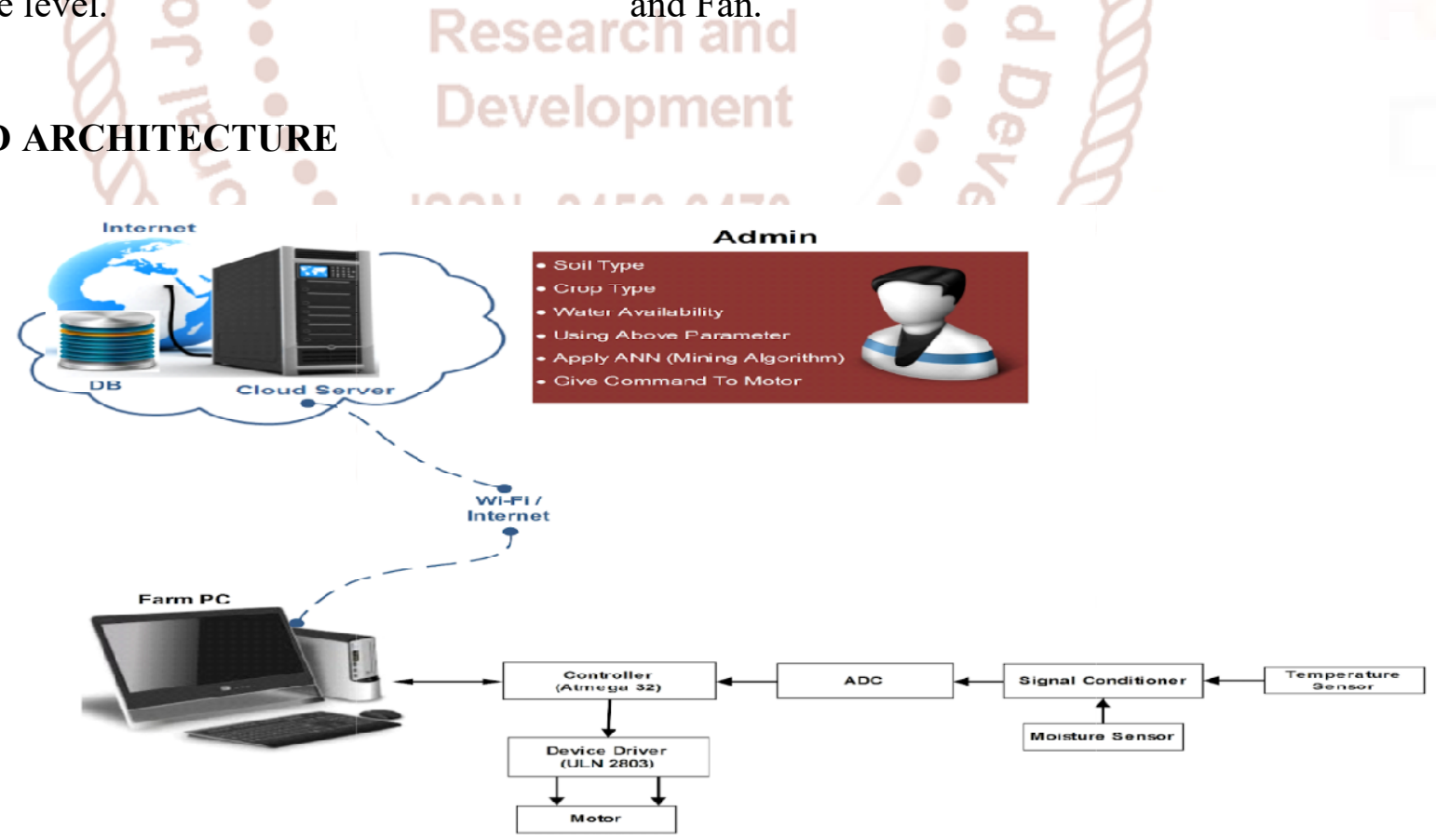

Fig 1: Arcitectural Design

Step 1: Source node is that which senses the input data from the sensors. Then this values transfer to the intermediate nodes for next process.
Step 2: In the intermediate node there are some sub nodes which processes next action on that input data that has taken from source node. Signal conditioner to send input to ADC.ADC is used to convert analog data to digital form. 
Step 3: After converting the data is passed to the controller. Controller transfers the data to the farm PC. Farm PC is the temporary storage.

Step 4: Farmer has to provide the information of soil type and crop type to that system. After collection all the data, it transfer towards to the cloud computing.

Step 5: The ANN algorithm is applied without generation any error it means that system will give accurate output. After comparing all data then it will move towards the controller.

Step 6: Controller is used here to control device driver. Its role is to give command to motor start. And provide the efficient water to whole farm or crop. Motor will be switch on for some period of time. It is automatic system so time is fixed automatically. Time period is dependent on input data.

\section{A. Source Node:}

Source node is that which senses the input data from the sensors. We are using temperature sensor and moisture sensor. Temperature sensor senses the temperature from farm and moisture sensor senses the moisture level in the farm, according to this values the system automatically decide the what amount of water should be provide to the farm. Then this values transfer to the intermediate nodes for next process.

\section{B. Intermediate Nodes:}

In the intermediate node there are some sub nodes which processes next action on that in-put data that has taken from source node. When sensors data came from source nodes that data is in the form of analog signals. So we need to convert that data into digital signal. So there is Signal conditioner to send input to ADC.ADC is used to convert analog data to digital form. After converting the data is passed to the controller. Controllers transfer the data to the farm PC. Farm PC is the temporary storage. Farmer has to provide the information of soil type and crop type to that system. After collection all the data, it transfer towards to the cloud computing.

\section{Destination Node:}

This is the last node which provides the system output. The ANN algorithm is applied with-out generation any error it means that system will give accurate output. After comparing all data then it will move towards the controller. Controller is used here to control de-vice driver. Its role is to give command to motor start. And provide the efficient water to whole farm or crop. Motor will be switch on for some period of time. It is automatic system so time is fixed automatically. Time period is dependent on input data.

\section{CONCLUSION}

Thus, the IoT agricultural applications are making it possible for ranchers and farmers to collect meaningful data. Large landowners and small farmers must understand the potential of IoT market for agriculture by installing smart technologies to increase competitiveness and sustainability in their productions. The demand for growing population can be successfully met if the ranchers as well as small farmers implement agricultural IoT solutions in a successful manner.

\section{REFERENCES}

1. H. Navarro-Hellin, R. Torres-Sanchez, F. SotoValles, C. Albaladejo- Perez, J. A. LopezRiquelme, and R. Domingo-Miguel, A wireless sensor architecture for efficient irri-gation water management, Agr. Water Man-age., vol. 151, pp. 64-74, 2015.

2. N. Harris, A. Cranny, M. Rivers, K. Smettem, and E. G. Barret-Lennard, Appli-cation of distributed wireless chloride sensors to environmental monitoring: initial results, IEEE Trans. Instrum. Mea s., vol. 65, no. 4, pp. 736744, Apr. 2016.

3. C. T. Kone, A. Hafid, and $M$. Boushaba,sPerformance management of IEEE 802.15.4 wireless sensor network for precision agriculture,IEEE Sensors J., vol. 15, no. 10, pp. 5734-5747, Oct. 2015.

4. M. Rivers, N. Coles, H. Zia, N. R. Har-ris, and R.Yates, How could sensor networks help with agricultural water management is-sues,IEEE 2015 Sensors Applications Symp., Zadar, Croatia, April 13-15, 2015.

5. J. Gutierrez, J. F. Villa-Medina, A. NietoGaribay, and M. A. Porta-Gandara, Automated irrigation system using a wire-less sensor network and GPRS module, IEEE Trans. Instrum. Meas., vol. 63, no. 1, pp. 166-177, Jan.2014. 
6. F. Viani, A. Polo, M. Donelli, and E. Giarola, A relocable and resilient distributed measurement system for electromagnetic ex-posure assessment, IEEE Sensors J., vol. 16, no. 11, pp. 4595-4604, Jun. 2016.

7. Kaewmard,N., \& Saiyod,S. (2014). Sensor data collection and irrigation control on vegetable crop using smart phone and wireless sensor networks for smart farm. 2014 IEEE Conference on Wireless Sensors (ICWiSE). doi:10.1109/icwise.2014.7042670

8. Nakutis, Deksnys, V., Jaruevicius,I., Marcinkevicius, E., Ronkainen, A., Soumi,P., ... Andersen,B. (2015). Remote Agriculture Automation Using Wireless Link and IoT Gateway Infrastructure. 2015 26th International Workshop on Database and Expert Systems Applications (DEXA). doi:10.1109/dexa.2015.37

9. S.R. Nandurkar, V.R. Dhool "Design and Development of Precision Agriculture system using Wireless Sensor network" IEEE international Conference on Automation 2014

10. Joaquin Gutierrez, Juan Francisco Villa-Medina "Automated Irrigation System using Wireless Sensor Network and GPRS module " IEEE Transaction,2013 